\title{
OS CUIDADOS DE ENFERMAGEM DURANTE O PROCESSO DE ABORTAMENTO NA ÓTICA DA TEORIA HUMANÍSTICA DE PATERSON E ZDERAD
}

\author{
THE NURSING CARE DURING THE ABORTION PROCESS FROM THE PERSPECTIVE OF \\ PATERSON AND ZDERAD'S HUMANISTIC THEORY
}

Mariana da Silva Häckl ${ }^{1}$

Vanessa Martinhago Borges Fernandes ${ }^{2}$

\footnotetext{
${ }^{1}$ Discente do Curso de Graduação em Enfermagem. Universidade do Sul de Santa Catarina - UNISUL Campus Pedra Branca - Palhoça (SC) Brasil. E-mail: marianahackl@gmail.com

${ }^{2}$ Enfermeira. Mestre em Enfermagem. Docente do Curso de Graduação em Enfermagem. Universidade do Sul de Santa Catarina - UNISUL - Campus Pedra Branca - Palhoça (SC) Brasil. E-mail: vambfernandes@gmail.com
} 


\title{
OS CUIDADOS DE ENFERMAGEM DURANTE O PROCESSO DE ABORTAMENTO NA ÓTICA DA TEORIA HUMANÍSTICA DE PATERSON E ZDERAD
}

\begin{abstract}
Este trabalho de Conclusão de Curso foi julgado adequado à obtenção do título de Bacharel em Enfermagem e aprovado em sua forma final pelo Curso de Enfermagem da Universidade do Sul de Santa Catarina
\end{abstract}

Palhoça, 30 de junho de 2020

Prof. MSc. Vanessa Martinhago Borges Fernandes - Orientadora Universidade do Sul de Santa Catarina

Prof. MSc. Elisabeth Flor de Lemos - Banca Examinadora Universidade do Sul de Santa Catarina

Prof. MSc. Jacqueline Gio Lúcio - Banca Examinadora Universidade do Sul de Santa Catarina

Enf. MSc. Larissa Rocha - Banca Examinadora Universidade do Sul de Santa Catarina 


\title{
RESUMO
}

Introdução: Preconizado na Política Nacional de Humanização, o cuidado integral nas situações de abortamento envolve o acolhimento, diagnósticos, emprego de tecnologias, orientações e esclarecimento sobre o planejamento familiar, delineando-se o questionamento: Quais os cuidados de enfermagem durante o processo de abortamento, da mulher hospitalizada, na Teoria Humanística de Paterson e Zderad? Objetivo: Conhecer os cuidados de Enfermagem durante o processo de abortamento da mulher hospitalizada na Teoria Humanística de Paterson e Zderad. Método: Pesquisa qualitativa, descritivaexploratória, realizada em duas instituições da Grande Florianópolis, uma pública e outra privada. A coleta de dados ocorreu com 18 enfermeiras da área Obstétrica, através de entrevista semiestruturada, no período de março de 2019 a fevereiro de 2020. A análise dos dados realizou-se através da análise de discurso, pela ótica da Teoria Humanística de Paterson e Zderad. Resultados: Originou-se 5 percepçõescategóricas: "Autopercepções sobre a legalização do aborto", "O processo de encontro sofrendo interferências devido cultura e crenças individuais", "O relacionamento intersubjetivo afetado pela tecnificação da assistência", "A presença agravada pela infraestrutura e recursos humanos inadequados" e "O chamado e a resposta transformados a partir da experiência/vivência". Conclusão: Compreendese que é imprescindível ao enfermeiro obter competência profissional desempenhando atitudes associadas a desenvoltura de habilidades e competências de figura sentimental, separando crenças, valores éticos e morais, buscando fortalecer a assistência prestada. A saúde do ser-mulher é questão de sobrevivência pessoal, é mais que a ausência de doença, é superação de um processo complexo, que não há como se estabelecer sem uma relação intersubjetiva entre enfermeiro e paciente.

Palavras-chave: Aborto. Cuidados de Enfermagem. Teoria de Enfermagem. Humanização do cuidado. Mortalidade materna.

\begin{abstract}
Introduction: Recommended in the National Humanization Policy, comprehensive care in abortion situations involves welcoming, diagnosing, using technologies, orientations and clarifying family planning, outlining and questioning: What nursing care during the abortion process, from hospitalized woman, in the Humanistic Theory of Paterson and Zderad? Objective: To learn about nursing care during the abortion process of hospitalized women in the Humanistic Theory of Paterson and Zderad. Method: Qualitative, descriptive-exploratory research, carried out in two institutions in Greater Florianópolis, one public and one private. A data collection took place with 18 nurses in the Obstetric area, through semi-structured interviews, without a period from March 2019 to February 2020. A data analysis carried out through discourse analysis, from the perspective of the Humanistic Theory of Paterson and Zderad. Results: Origin: 5 technical-perceptions: "Self-perceptions about the legalization of abortion", "The encounter process with interferences related to culture and individual beliefs", "The intersubjective relationship affected by the technology of assistance", "The presence aggravated by occupation "and inadequate human resources" and "the call and the response transformed from experience". Conclusion: Understand that it is essential for nurses to obtain professional skills by performing attitudes related to the development of skills and competencies of sentimental figures, separating beliefs, ethical and moral values, seeking assistance. Human health is a matter of personal suffering, it is more than the absence of disease, it is overcoming a complex process, which cannot be defined without an intersubjective relationship between nurse and patient.
\end{abstract}

Key words: Abortion. Nursing care. Nursing Theory. Humanization of care. Maternal mortality 


\section{INTRODUÇÃO}

Abortamento é definido como interrupção da gravidez antes de atingir a viabilidade fetal. Temse como limite para caracterizar a perda de conceptos de até 22 semanas ou 500 gramas. Sendo "abortamento" o processo e "aborto" o produto eliminado, o feto (MACHIN et al., 2019).

O cuidado integral no processo de abortamento, preconizado na Política Nacional de Humanização, envolve desde o acolhimento, diagnósticos das reais necessidades de cada usuária, o emprego de tecnologias apropriadas para a terapêutica, bem como a inclusão de orientações e esclarecimento sobre o planejamento familiar, visando a escolha e adoção de um método contraceptivo adequado a cada situação, sendo uma das principais diretrizes das práticas de cuidado em saúde, e se processa segundo a teoria denominada por Paterson e Zderad como intersubjetiva, a qual diz respeito à compreensão do acolhimento na relação com a usuária, construindo vínculos interpessoais mediante a uma escuta solidária e atenta aos sofrimentos pela abertura do exercício clínico ao plano coletivo e relacional. (MACHIN et al., 2019).

Atualmente no Brasil, o aborto é definido como prática ilegal nos artigos 124, 125, 126 e 127, conforme Código Penal Brasileiro (BRASIL, 1940), cuja classificação é de fetos nascidos com menos de $500 \mathrm{~g}$ ou antes de 20 semanas de gestação completas em sequência à expulsão uterina, sendo desprovido de qualquer probabilidade de sobrevida (SANTOS, 2019), exceto em duas circunstâncias: em casos de risco de vida materna e casos de estupro (BRASIL, 1940).

De acordo com a decisão do Supremo Tribunal Federal, 2018, a Arguição de Descumprimento de Preceito Fundamental (ADPF) 54 estabeleceu, no entanto que não deve ser considerado igualmente como aborto a interrupção terapêutica induzida na gestação de um feto anencéfalo. Perante esses casos, o procedimento é efetuado pelo o Sistema Único de Saúde (SUS) (LUNA, 2018).

Existem alguns termos, tais como: "violência obstétrica", "tratamento desumano" e "desrespeito" e "abuso" que têm sido utilizados por diversas organizações para caracterizar os maus tratos durante a assistência em saúde. Sabe-se que ainda não existe um consenso quanto ao melhor termo e conceito de violência institucional, porém esse se configura em um detalhe irrelevante quando comparado à potencialidade que esse ato pode vir a causar como sofrimento à mulher, influenciando negativamente a qualidade do cuidado prestado e atuando como barreira na utilização do serviço de saúde. As mulheres que passam por um processo de abortamento provocado procuram os profissionais de saúde buscando apoio, privacidade, confidencialidade e respeito durante seu atendimento, porém não é isso que encontram em países onde o aborto não é permitido (MADEIRO, 2017).

De acordo com a Organização Mundial de Saúde (OMS), a maior causa de mortalidade materna é resultante de complicações como hipertensão, hemorragia, infecções puerperais, doenças do aparelho circulatório, parto, puerpério e aborto. Em relação ao aborto a maior incidência está presente nas mulheres de baixo nível socioeconômico e de raça/cor preta (JORNAL DA USP, 2019). 
Em um inquérito realizado com amostra probabilística de 2.365 mulheres de todo o Brasil, em 2010, revelou que 53\% daquelas que provocaram o aborto informaram ter sofrido algum tipo de violência durante a internação hospitalar. Sendo que o impacto dessa violência na assistência às complicações decorrentes do aborto provocado ainda é pouco explorado no Brasil (MADEIRO, 2017).

A enfermeira, profissional responsável por gerenciar o cuidado durante a permanência da mulher no hospital, tem a real condição de organizar o trabalho da equipe e sensibilizar os trabalhadores para que busquem adequar as atividades assistenciais às atividades educativas, visando capacitar as mulheres para que se sintam encorajadas a cuidar de si. Estas ações são apoiadas por Políticas Públicas e desdobram como estratégias resolutivas para a diminuição da demanda por sequelas de aborto (SILVA et al., 2019).

A Teoria Humanística de Enfermagem proposta na década de 1960 pelas enfermeiras Josephine Paterson e Loretta Zderad incita a reflexão do questionamento sobre as experiências vivenciadas no campo da enfermagem, trabalhando com a experiência existencial do conhecimento humano (CRUZ et al., 2017).

Para melhor compreender este fenômeno e como se desenvolve esta interação humana, entre profissional e paciente utilizaremos a Teoria Humanística de Paterson e Zderad. A enfermagem Humanística está estruturada tendo como elementos os seres humanos que são a equipe de enfermagem e o cliente, que se encontram para um "vir a ser" a partir das experiências vividas, onde a enfermeira vivencia o "estar com" e o "fazer com", com uma meta que é a de proporcionar o "bem-estar" e o "estar melhor" ao cliente (VASQUES et al, 2020).

A relevância deste estudo se justifica pelo alto índice de abortamento no Brasil, na morbidade e mortalidade gerada por este e pelo despreparo dos profissionais em lidar com estas situações e sofrimento, buscando a excelência para o tratamento do profissional de enfermagem neste contexto. $\mathrm{O}$ estudo sobre o tipo dos cuidados que vem sendo prestada durante o processo de abortamento à mulheres internadas em unidades hospitalares de referência e a relação destas percepções sobre o ponto de vista da Teoria Humanística pode vir a contribuir para a melhoria das práticas de cuidado de enfermagem em uma área que requer sensibilidade para compreender o outro e trabalhar segundo suas necessidades.

Sendo assim, a proposta delineada traz à tona o seguinte questionamento: Quais os cuidados de enfermagem durante o processo de abortamento, da mulher hospitalizada, na Teoria Humanística de Paterson e Zderad? Tendo como objetivo, conhecer os cuidados de enfermagem durante o processo de abortamento da mulher hospitalizada na Teoria Humanística de Paterson e Zderad.

\section{MÉTODO}

Estudo de abordagem qualitativa, do tipo exploratório-descritivo. A pesquisa foi realizada com profissionais de enfermagem de duas instituições da Grande Florianópolis: uma maternidade pertencente a um hospital público e uma maternidade pertencente a uma clínica privada. No hospital público o estudo 
foi realizado nas Unidades de Emergência Obstétrica e/ou Centro Obstétrico, e na clínica privada, foi realizado na Unidade de Internação Cirúrgica, onde as mulheres ficam internadas durante o processo de abortamento.

O presente estudo obteve a participação de 18 Enfermeiros das duas instituições, sendo 10 da instituição privada e 8 da instituição pública. Tendo como critérios de inclusão: profissionais de enfermagem que trabalhem há mais de um ano na Unidade. Como critério de exclusão: os profissionais que estão afastados do serviço por motivo de férias, folga, licença ou outro.

Os dados foram coletados através de entrevista individual, semiestruturada, com roteiro, sendo audiogravadas e o conteúdo transcrito no Programa Microsoft Word. A coleta de dados ocorreu no período de março do ano de 2019 a fevereiro do ano de 2020. A análise dos dados ocorreu através da análise de discurso das entrevistas realizadas, sob a ótica da Teoria Humanística de Paterson e Zderad.

O projeto foi submetido e aprovado junto ao Comitê de Ética em Pesquisa (CEP) da Universidade do Sul de Santa Catarina (UNISUL), com parecer consubstanciado CAAE 04341718.5.0000.5369 e respeitou os aspectos éticos da resolução n. 466/2012 (BRASIL, 2012). As participantes assinaram termo de consentimento livre e esclarecido, em duas vias, e suas identidades foram preservadas utilizando codinomes de heroínas fictícias, lutadoras e guerreiras de jogos de luta que possuem muita força para enfrentarem suas batalhas diárias, relacionado às rotinas e sobrecargas profissionais.

\section{RESULTADOS}

Os participantes do estudo foram constituídos por 18 enfermeiras de duas instituições, sendo 10 da instituição privada e 8 da instituição pública. Todas são do sexo feminino, com faixa etária média de 36 anos de idade. Quanto ao nível de escolaridade, onze (11) possuem especialização na área de Obstetrícia e Ginecologia, duas (02) na área de Urgência e Emergência, uma (01) na área Saúde da mulher, uma (01) na área de Educação em enfermagem. Duas (02) possuem mestrado, e uma (01) doutorado. Referente ao estado civil, 11 são casadas e 07 são solteiras, destes, 55\% do grupo são mães. Suas religiões abrangem o Catolicismo (13), Evangelismo (2), Umbandismo (1) e Ateísmo (2).

A análise dos dados adquiridos resultou no delineamento de 05 percepções-categóricas: "Autopercepções sobre a legalização do aborto", "O processo de encontro sofrendo interferências devido cultura e crenças individuais", "O relacionamento intersubjetivo afetado pela tecnificação da assistência", "A presença agravada pela infraestrutura e recursos humanos inadequados" e "O chamado e a resposta transformados a partir da experiência/vivência". 


\section{AUTOPERCEPÇÕES SOBRE A LEGALIZAÇÃO DO ABORTO}

A categoria 1, suscitou duas subcategorias: "a favor do aborto" e "contra o aborto". Dentro das subcategorias apresentam-se os códigos: "não é contra ao aborto", "sentimento de revolta com o relato de aborto legal", "tem muito julgamento", "é a favor do aborto legalizado" e "é a favor de legalizar o aborto". Revelando diversos pontos de vista polêmicos, crenças, culturas e individualidades pertinentes ao tema.

\section{A favor do aborto}

Nesta subcategoria foi relatado pelas enfermeiras em sua individualidade uma opinião com base em suas vivências aprovando o aborto, pois existem diversas situações na qual pacientes foram expostas, sejam originadas de fatores legais, ou por uma decisão particular, que por motivos pessoais, necessitou a realização de intervenção. Algumas ainda defendem a legalização do mesmo, perante a justiça e sociedade. Em conformidade com relatos a seguir:

Então, eu sou a favor, às vezes por eu ser obstetra o pessoal fala: meu Deus, como assim? Uma enfermeira obstetra sendo a favor do aborto? E é realmente por isso mesmo, sabe? Eu tento reforçar a questão, me colocar no lugar da mulher. Se ela não quer, se ela não está preparada, se não é isso que ela quer para ela, a gente sabe que tem até um certo ponto da idade gestacional que o bebê ainda não está desenvolvido, que ela pode sim fazer, que para o bebê não é um sofrimento, não é um assassinato, entendeu? Ela quer abortar? Ela vai abortar, ela é dona do corpo dela, ela é dona da história dela (Ling Xiaoyu, é a favor do aborto).

[...] é porque envolve muita coisa e o pessoal olha só para o bebê, e a mãe que está matando a criança? Entendeu? Ignora todo o histórico da família, a estrutura, desenvolvimento, educação, saneamento, como se não precisasse, desde que a criança nasça, né? Como se a sociedade não ignorasse essas crianças, que a gente vê aí em creche, criança marginalizada, sendo apontada como marginal, que na verdade são. Faria se fosse comigo, se eu não quisesse, se eu não tivesse condições (Ling Xiaoyu, é a favor do aborto).

[...] sou a favor no caso de estupro, se não, não. Eu acho que a mulher tem que se cuidar antes para não engravidar, não abortar o feto depois que ele já tem vida. Mas respeito também, né? [...] (Kitana, é a favor do aborto legalizado).

\section{Contra o aborto}

Nesta subcategoria foi explanado pelas enfermeiras em sua individualidade uma opinião com base em suas vivências reprovando o abordo, não importando as situações na qual as pacientes foram expostas, sejam originadas de fatores legais, ou por uma decisão particular, nada justifica a retirada de uma nova vida que se forma. Algumas ainda defendem que esse posicionamento se configura por 
crenças e questões culturais das próprias enfermeiras. Porém, mesmo mediante esta opinião, as profissionais realizam o trabalhado dentro do protocolo hospitalar, ressaltando que por muitas vezes deixam de lado o atendimento humanizado. Em conformidade com relatos a seguir:

[...] eu sou contra, radicalmente contra. A não ser com algumas situações, mas, assim, eu acredito que a partir do momento que une um óvulo e um espermatozoide, eu acho que ali se inicia uma vida. Então eu acho que a gente tem que respeitar isso aí, né? Eu acho que a gente está indo contra um processo que é natural da vida. Eu acredito muito em Deus, o que é para ser será, né? Então eu acredito muito nisso, eu sou contra o aborto (Nina Williams, é contra ao aborto).

Eu sou contra, porque, assim, imagina, a gente vive em uma era em que existem vários meios para se evitar uma gestação. Claro, ah, de repente, aconteceu isso, mas assim, não tem cabimento sabe? (Rainbow Mika, é contra ao aborto).

[...] eu sou contra o aborto. Eu acho que tem outras maneiras de evitar ou resolver, você não precisa ficar com a criança. Pode gerar e doar. Mas isso aí vai de cada um. É complicado, eu acho, é bem complicado, não dá para julgar (Li Mei, é contra ao aborto).

[...] eu, sou contra o aborto, esse que é provocado. Tá? Por quê? Porque eu vim de uma formação religiosa, eu sou católica, e aprendi que não é legal, é pecado praticar o aborto (Jade, é contra ao aborto).

\section{O PROCESSO DE ENCONTRO SOFRENDO INTERFERÊNCIAS DEVIDO CULTURA E}

\section{CRENÇAS INDIVIDUAIS}

$\mathrm{Na}$ categoria 2 as enfermeiras, revelam suas perspectivas/pontos de vista, baseados principalmente em crenças culturais e algumas religiosas, associado a assistência as mulheres em processo de abortamento. Visando implementar uma assistência humanizada na medida do possível e igualitária a cada situação, porém devido a fatores pessoais, suprimem inconsequentemente ou conscientemente uma assistência adequada, ou seja, algumas obtém dificuldade em aplicar a amabilidade mediante alguns casos. Em conformidade com relatos a seguir:

Eu acho que, assim, quando acontecem os casos provocados a gente acaba pensando: "não, não merece o cuidado, não merece isso", a gente acaba julgando, só que a gente também não sabe o por trás, porque causou, porque ela fez, a gente não sabe. Então a gente julga sem saber, a gente pensa: "não, ela não deveria ter feito isso", "não, ela está errada", "não, ela não deveria" e a gente tenta não mudar o jeito de atender, né? (D'Vorah, influencia na assistência).

Dependendo de como a gente encara isso, influencia na assistência sim, porque a gente percebe que tem algumas pessoas que ficam mais secas... eu acho que o problema maior não é nem não ter o atendimento humanizado, é o julgamento, né? Porque eu, como frequento hoje em dia a religião espírita, que também tem toda uma carga espiritual que envolve isso, mas, assim, é muito complicado, eu acho que cada um sabe onde seu sapato aperta, né? 
(Mileena, crença religiosa influencia na assistência).

[...] eu acho que cada um sabe o que faz da sua vida, se ela estava em plena consciência do que ela estava fazendo, mas claro que dá uma revolta na gente [...] (Asuka Kazama, revolta).

[...] então... é porque é meio estranho...porque, assim, a enfermagem é saúde, saúde você lembra vida, ou possibilitar uma vida, que a pessoa carrega... E aí, o aborto é retirada da vida. Para mim, acho que é completamente contraditório. Aí você olha os bebês na Neo, uns "tiscos", guerreiros, dia a dia ali lutando para sobreviver, aí você vê uma pessoa que está tirando a vida de um, é complicado (Li Mei, julgamento).

\section{O RELACIONAMENTO INTERSUBJETIVO AFETADO PELA TECNIFICAÇÃO DA} ASSISTÊNCIA

A categoria 3 trata de como as participantes expõem os desafios de suas vivências assistenciais e de como colocam a prioridade na assistência técnica, deixando a humanização a desejar. Dentro desta categoria, apresentam-se os códigos: "é automático"; "é atendida como as outras"; "não possuem disponibilidade para dar atenção a essas mulheres"; e, "procuram sempre prestar o diálogo na medida do possível".

As participantes relatam que só é possível fornecer um cuidado dedicado quando a unidade não se encontra com lotação, caso contrário, a relação com o paciente se torna superficial, pois são priorizados os casos mais graves e os nascimentos que estão ocorrendo. Em consequência disso, os profissionais não dão a devida importância para a necessidade de suporte psicológico das mulheres que passam pelo processo de abortamento.

Outro ponto evidenciado são os recursos humanos indisponíveis para o atendimento especializado aos pacientes, prejudicando a assistência. Mesmo que o profissional se esforce, ainda terá de efetuar a escolha conforme a priorização naquele momento. Em conformidade com relatos a seguir:

Você sempre vai priorizar aquela que está parindo, aquela que vai ter o bebê vivo. E, muitas vezes, a gente deixa um pouco de lado aquela que está em processo de abortamento, que sofreu um abortamento [...] (Jade, carência assistencial).

[...] isso é horrivel, é péssimo. Nós trabalhamos com o mínimo do mínimo e a gente acaba priorizando, e dando maior importância à paciente que é mais grave, ou ao nascimento, sabe? A gente é obrigada a escolher quem precisa de mais cuidado, porque a gente não consegue atender todo mundo como merece. Por causa do quantitativo de funcionários. [...] É mais ou menos isso, a gente não consegue ver todo mundo, a gente não consegue ficar com duas mulheres ao mesmo tempo (Sonya Blade, escassez de funcionários/carência assistencial).

[...] mas, com certeza às vezes pensamos, ah, de repente ela gostaria de ser mais ouvida, mas eu tenho que fazer tal procedimento, daqui a pouco já tenho que fazer outro procedimento, você acaba se atropelando. Mas a gente 
sempre tenta prestar um bom atendimento. Claro que, se a gente tivesse um número suficiente de Enfermeiros, seria muito diferente [...] (Cassie Cage, escassez de funcionários).

[...] você consegue atender, você consegue fazer as condutas necessárias para essa paciente, porém às vezes fica faltando esse ponto essencial que ela precisa, né? Que é principalmente isso, a atenção da psicologia, eu acho que falta. Mas em conduta, sim, acredito que a gente consegue fazer um bom trabalho (D'Vorah, carência assistencial).

A prioridade aqui são as mulheres que estarão em trabalho de parto, nas de aborto, a gente nem consegue dar atenção a essas mulheres. Infelizmente. Quando é uma idade gestacional mais avançada, aí sim, aí é diferente. Por exemplo, tem uma puérpera agora no leito 7 , então a gente fez uma cartinha de despedida e fez o carimbo do pezinho [...] (Sonya Blade, carência assistencial).

\section{A PRESENÇA AGRAVADA PELA INFRAESTRUTURA E RECURSOS HUMANOS} INADEQUADOS

A categoria 4 suscitou duas subcategorias: "Estrutura afetada para prestar assistência humanizada" e "Sobrecarga de função afeta diretamente a assistência".

\section{Estrutura afetada para prestar assistência humanizada}

Nesta subcategoria as profissionais empregam os desafios da infraestrutura afetada em correlação ao atendimento humanizado, destacando quais foram os fatores determinantes para não conseguir fornecer assistência humanizada adequada e de que maneira conseguem se adaptar e se organizar tecnicamente. Em conformidade com relatos a seguir:

[...] ah, desde o atendimento, lá embaixo, até as instalações. Não tem instalação para elas direito. Não tem Enfermeiro, não tem equipe completa, sempre. Tem dia que tem três à noite, só. Tem dia que não tem Enfermeiro (Cammy, carência grave de infraestrutura).

[...] acaba influenciando na estrutura física também, muitas vezes a paciente que sofreu um aborto vai ficar em um ambiente junto com uma mulher que acabou de parir, com uma que está grávida... [...] Então isso é desumano, mas a gente não tem um outro espaço para recuperar uma paciente de curetagem [...] (Jade, práticas desumanas na assistência ao abortamento).

[...] no plantão passado, foi no sábado, a unidade estava cheia se chegou alguma, não sobe para unidade, fica lá embaixo, sabe? [...] Vão empilhando, provavelmente, se não tem infecção, alguma coisa, eles podem mandar para casa [...] (Cammy, carência grave de infraestrutura).

[...] A instituição está ciente, quer mudar, mas por falta de estrutura não está conseguindo. Quem sabe agora, está tendo a reforma, eles vão ver se aumentam leitos para tentar evitar isso (Ling Xiaoyu, objetivo de melhoria 
perante a reforma).

O material, a unidade está precisando bastante. Que tipo de material? Até travesseiro. Travesseiros, tem poucos. Acho que teria que ter, já que estamos disponibilizando a humanização da assistência, o acompanhante precisaria de uma acomodação adequada, pelo menos uma poltrona decente, não uma cadeira que, às vezes, não tem encosto. Então precisaria de uma poltrona decente. Os quartos não foram feitos para humanizar, por quê? (Li Mei, carência de infraestrutura).

\section{Sobrecarga de função afeta diretamente a assistência}

Nesta subcategoria as profissionais evidenciam como a sobrecarga de função ocasionada pela escassez de mão de obra, interfere diretamente na prestação de uma assistência humanizada. Em conformidade com relatos a seguir:

[...] a carência, em questão de RH, de Enfermeiros, é bastante grande. Nós atuamos em um setor em que temos mais de 80 pacientes, somando as duas unidades aqui e em muitos momentos atuamos em duas enfermeiras, e, às vezes até em uma enfermeira, somente, para prestar esse atendimento a todo esse povo. Então é uma sobrecarga de trabalho bem grande. Mas, na medida do possivel, a gente tenta sempre dar um bom atendimento (Ling Xiaoyu, sobrecarga de função).

A gente sempre procura prestar um atendimento humanizado, só que às vezes, devido à demanda, correria, acaba sendo um pouquinho difícil (Kitana, demanda alta, correria).

[...] a gente não consegue oferecer um bom suporte... E a gente, além de as acompanhar, acompanha também as gestantes, o setor da emergência, todos os outros setores e a internação. [...] é tudo muito rápido para uma coisa que vai marcar a vida dela ou que está sendo um pesadelo para ela (Ling Xiaoyu, escassez de profissionais).

\section{O CHAMADO E A RESPOSTA TRANSFORMADOS A PARTIR DA} EXPERIÊNCIA/VIVÊNCIA

$\mathrm{Na}$ categoria 5, as participantes expõem que suas vivências/experiências foram fatores determinantes para conseguir fornecer uma assistência um pouco mais adequada de acordo com as necessidades de cada situação. Salientando, que há necessidade de uma capacitação para lidar com a mulher que está passando por este processo delicado, pois acabam atendendo os casos pelas perspectivas vivenciais. Muitas relatam, que ainda não sabem como lidar com algumas situações e que o tempo e a vivência as tornam mais "frias". Em conformidade com relatos a seguir:

[...] porque a gente, desde a universidade, não aprende a lidar com essas situações, a gente só chega de cara e passa a lidar, né? Começa a criar uma capa protetora, né? Não é minha família. Se eu pegar alguém que é minha 
família, eu acho que, sim, eu posso chorar. Mas, assim, eu separo bem, isso eu separo bem. É difícil, mas a gente tem que aprender (Chun-Li, cria uma capa protetora).

[...] eu não me considero capacitada via instituição de ensino, por exemplo. Como receber a paciente que abortou ou que sofreu o aborto, não tem, a gente aprende no dia a dia. Eu sou diferente das minhas colegas, toda pessoa é diferente, então a gente meio que atende de acordo com as nossas experiências e perspectivas de vida [...] (Ling Xiaoyu, vivência trouxe a capacitação).

É, a gente adquire, mas buscando, tá? Porque senão, não. A gente não é preparada. Muita coisa falta na formação, principalmente em questão da Psicologia da assistência, que a gente trabalha com assistência técnica, mas a psicológica às vezes é maior do que a técnica, entendeu? Às vezes a técnica só auxilia ali e o turbilhão é a psicológica. E a gente não tem um equilíbrio ali nas duas coisas, sabe? A gente vai muito pela técnica, técnica, teoria da prática, e nada da Psicologia. (Ling Xiaoyu, carência da Psicologia assistencial).

[...] na verdade, a gente não tem estrutura, o profissional, não tem uma estrutura de apoio. Simplesmente cai de paraquedas na nossa unidade. Mas a gente não tem rede de apoio na verdade. É difícil, é bem difícil (Rainbow Mika, vivência trouxe a capacitação).

[...] era uma questão que me incomodava muito e eu fui atrás disso. Minha dissertação de mestrado foi sobre perda gestacional, mas por isso, porque a gente não teve capacitação pelo Estado, nada disso (Sonya Blade, estudo ampliou capacitação).

\section{DISCUSSÃO}

Assim como na Teoria Humanística de Paterson e Zderad incitaremos a reflexão, exploração e questionamentos sobre as vivências das enfermeiras que assistem o ser-mulher em seu processo de abortamento. Destacando dentre os achados a carência na relação intersubjetiva sujeito-sujeito, ou seja, no cuidado humanizado com mulheres em processo de abortamento, através da dificuldade no diálogo, a imprudência direcionada ao ato técnico e principalmente a discriminação do ato de julgar ou pré-julgar a situação.

$O$ atendimento deve ser efetuado na sua integralidade, exigindo dos profissionais de enfermagem um cuidado acolhedor e não discriminador, pois mesmo o aborto sendo ilegal no país, o cuidado perante essa mulher não deve ser negligenciado. A partir do momento em que a paciente notifica sua entrada na maternidade, os profissionais devem estar qualificados, visando fornecer uma assistência integral e de qualidade, com abordagem clara e ética, visto que, a atenção de qualidade é um direito da usuária, sobretudo diante da situação de vulnerabilidade física e emocional, seja ocasionado por um parto, um aborto espontâneo ou provocado (LIMA et al., 2017).

Lima e outros (2017) ainda destacam que a assistência a essas mulheres também não pode ser mecanizada, ou seja, fazer uso apenas de uma abordagem técnica, sendo que, há fatores situacionais 
envolvidos, que devem ser evidenciados, sendo de grande relevância o profissional de enfermagem exercer a sua competência multiprofissional, respeitando, oferecendo escuta ativa e prestando o devido acolhimento humanístico.

Quando se trata de saúde, os procedimentos técnicos do exercício profissional se tornam um obstáculo para a implementação da humanização. Sendo fundamental que o profissional compreenda a mulher em seus múltiplos conceitos, tal como sua história social, conjugal, angústias, preocupações, norteando o sentido do acolhimento. O que na Teoria Humanística refere o olhar do ser-mulher no seu mundo.

As enfermeiras desta pesquisa também evidenciam diversos pontos de vista a serem refletidos, impondo crenças, culturas e individualidades que afetam consciente ou inconscientemente o fato de prestar um atendimento de qualidade ou igualitário a essas mulheres ressaltando que a qualidade para com a atenção humanizada relacionada ao aborto no Brasil, ainda é pouco evidenciada. Segundo a Teoria Humanística, o ser humano, é um ser que se relaciona com os outros no tempo e no espaço, que é capaz de estar aberto a opções e a autopercepção como valor e como manifestação do seu passado, presente e futuro, permitindo sua individualidade e opiniões próprias.

Corroborando com estudo apontado, Pereira (2018), descreve que a análise em torno do aborto envolve muitas questões éticas, culturais e religiosas. A contradição que envolve a questão do aborto manifesta-se quando as crenças pessoais se chocam com as leis que tentam proteger os direitos da mulher. Apesar de questões de encargo pessoal entrar em conflito no momento da decisão de a paciente realizar o aborto, para o profissional que está sendo responsável pelo atendimento, por estar relacionado à uma questão de morte do feto, as opções devem ser expostas sem tornar evidente sua satisfação ou insatisfação perante a escolha da mesma (PEREIRA, 2018).

A pesquisa também ressalta disparidades nas opiniões quanto a legalização do aborto. Para Santos e outros (2020), os profissionais envolvidos, principalmente em situações complexas, necessitam quebrar paradigmas como o preconceito, sejam morais e/ou religiosos, assumindo uma postura ética de valor e respeito, efetuando uma assistência de qualidade do início ao fim do atendimento prestado. Além disso, torna-se necessário que as pacientes sejam assistidas não apenas de maneira integral, mas que as informações pertinentes às políticas que envolvem o planejamento familiar estejam sendo repassadas a essas mulheres, a fim de evitar que novos episódios de abortamento aconteçam.

Um outro fator implicado no estudo, revela que a ausência da fidedignidade das informações prestadas aos profissionais por parte dessas mulheres é um dos fatores inconvenientes, visto que por isso, muitos profissionais não se sentem confortáveis em proceder com o abortamento. Apesar da possibilidade de a mulher abortar nos casos previsto por lei, a prática do aborto clandestino tem sido frequente no país, refletindo uma grande lacuna entre o que é legal e as ações de mães que abortam (SANTOS et al., 2020).

O Ministério da Saúde, visando adotar a prática da humanização às mulheres que realizam o aborto em tentativa de diminuir o número de vítimas, sancionou em 2005 uma norma técnica de atenção 
humanizada ao aborto. A norma também orienta os profissionais para que atuem de maneira humanizada, sem preconceitos ou objeções acerca do assunto. Contudo, as normas precisam ser aperfeiçoadas ao estabelecimento com parâmetros mínimos de adequação e indicadores de avaliação, bem como já existentes na atenção ao pré-natal e ao parto (AQUINO, et al., 2012).

As enfermeiras deste estudo destacam a carência de funcionários, a carência de capacitação profissional e a influência da infraestrutura no atendimento prestado, gerando uma sobrecarga e um ambiente de trabalho estressante, o que segundo a Teoria Humanística dificulta a presença e a relação entre sujeito-sujeito. De acordo com estas afirmativas, Santos e outros (2020), apontam que as limitações existentes pertinentes a execução de um planejamento visando a prática humanística no processo de abortamento, abrangem a carência de um espaço físico adequado, assim como a falta de capacitação profissional, quebra de ética do sigilo profissional e a dificuldade no relacionamento interpessoal. A capacitação dos profissionais que lidam com o atendimento a essas mulheres, deve garantir competência a nível pessoal, a fim de prestar uma assistência de boa qualidade de acordo com os padrões e as normas nacionais.

$\mathrm{Na}$ intenção de garantir a qualidade na assistência prestada ao abortamento se faz necessário compreender a importância de uma supervisão apropriada, garantia da competência e avaliação constante. Pois a carência no conhecimento dos profissionais reportado a legislação e as políticas públicas efetivaria a criação de barreiras, prejudicando a qualidade do atendimento. Já diante dos serviços prestados, evidencia-se a privacidade, a dignidade, o respeito, a sensibilidade, às necessidades e aos direitos das mulheres, em especial, as de condições menos favorecidas, vulneráveis e marginalizadas. Para efetivação, os profissionais necessitam estar capacitados assim como instalações precisam ser adequadas promovendo garantia, segurança, boa qualidade e acessibilidade aos serviços (SANTOS et al., 2020).

Para que haja um chamado e uma resposta satisfatória, ambicionando uma adequada assistência ao processo de abortamento, visando o desenvolvimento do bem-estar e do vir-a-ser (estimulação do potencial humano do ser-mulher). Sendo assim, chamamos a seguinte reflexão:

Ainda há um caminho a ser percorrido para que os Enfermeiros não atuem somente com uma visão biológica em torno do aborto, mas que receba formação para uma visão moral, ética e psicológica, a fim de ofertar ao cliente uma ajuda humanizada de qualidade (PEREIRA, 2018). 


\section{CONSIDERAÇÕES FINAIS}

Os conceitos da Teoria Humanística de Paterson e Zderad nos auxiliaram a compreender que os Enfermeiros que estão na assistência direta ao ser-mulher em processo de abortamento precisam valorizar a necessidade da interação humana. Por isso, é imprescindível a aplicação da Teoria Humanística de Paterson e Zderad como prática sistematizada para obtenção de uma assistência segura, efetiva e holística.

Para o encadeamento na geração de vínculo com o ser-mulher em processo de abortamento compreendeu-se que é imprescindível ao enfermeiro obter competência profissional desempenhando atitudes associadas a desenvoltura de habilidades e competências de figura sentimental, separando suas crenças, valores éticos e morais diante da relação assistencial.

A discussão da teoria humanística pela equipe de enfermagem está em processo de desenvolvimento. Esta permite um olhar diferenciado para com o ser-mulher, propiciando o envolvimento, empatia e compreensão, designando uma assistência integral de qualidade, aberta ao diálogo vivido conforme Paterson e Zderad. Buscando fortalecer a assistência prestada, ampliando o nível do conceito humanizado, gerando autonomia ao gestor (encontro-vivido e dialogado), em base a referência da escolha de um melhor cuidado prestado.

É fundamental que o Enfermeiro responsável pela gestão da equipe de enfermagem, dirigente do diálogo vivenciado, retifique as novas estratégias de adesão as práticas de educação continuada humanizada, objetivando uma assistência digna e de qualidade, enfatizando respeito e fortalecendo o elo entre Enfermeiro e paciente no diálogo vivido.

A saúde do ser-mulher é questão de sobrevivência pessoal, é mais que a ausência de doença, é superação de um processo complexo, que não há como se estabelecer sem uma relação intersubjetiva entre Enfermeiro e paciente. Por isso, o Enfermeiro deve passar pelas 5 fases do processo de cuidar de Paterson e Zderad: a preparação do enfermeiro cognoscente para chegar ao conhecimento; conhecer intuitivamente ao outro; conhecer cientificamente o outro; sintetizar complementarmente as realidades conhecidas ou comparar realidades múltiplas, examinar os dados e a experiência do paciente à luz do conhecimento científico, sintetizar uma visão; e da sucessão das multiplicidades à unidade paradoxal com o processo interno do enfermeiro, compreender o processo integral, que a partir desta pesquisa, vislumbra a necessidade de capacitação profissional, o conhecer cientificamente a situação, além do tempo de experiência já vivenciado, desenvolver a intuição através do encontro, sintetizando as realidades conhecidas e refletindo constantemente as diversas visões. Desse modo, salienta-se a necessidade de rever o ambiente interno de cada trabalhador, assim como sua percepção de cuidado, de si e do outro (intersubjetivo) e seu nível de conhecimento voltado a capacitação no âmbito humanístico, de modo que não realize ações automáticas, mas antes possa sensibilizar-se com a dor do outro, proporcionando-lhe uma assistência digna e integral. 


\section{REFERÊNCIAS}

AQUINO, Estela M. L. et al. Qualidade da atenção ao aborto no Sistema Único de Saúde do Nordeste brasileiro: o que dizem as mulheres? Ciência e Saúde Coletiva, Rio de Janeiro, v. 17, n. 7, p. 17651776, jul. 2012. Disponível em: http://www.scielo.br/scielo.php?script=sci_arttext\&pid=S141381232012000700015\&lng=en\&nrm=iso. Acesso em: 17 mai. 2020.

BRASIL. Decreto-lei n. 2.848, de 7 de dezembro de 1940. Brasília, 1940. Disponível em: http://www.planalto.gov.br/ccivil_03/ Decreto-Lei/Del2848compilado.htm. Acesso em: 26 set. 2018.

BRASIL. Supremo Tribunal Federal. Arguição de Descumprimento de Preceito Fundamental. Anencefalia. Brasília-DF, 2012. Disponível em:

http://www.stf.jus.br/arquivo/informativo/documento/informativo661.htm\#ADPF\%20e\%20interrup\% C3\%A7\%C3\%A3o\%20de\%20gravidez\%20de\%20feto\%20anenc\%C3\%A9falo\%20-\%2026. Acesso em: 27 set. 2018.

CRUZ, Déa Silvia Moura da, COLLET, Neusa, ANDRADE, Edineide Maria Costa de, NÓBREGA, Vanessa Medeiros da, \& NÓBREGA, Maria Miriam Lima da. Vivências de mães de crianças diabéticas. Escola Anna Nery, Rio de Janeiro, v. 21, n. 1, e20170002, 2017. Disponível em: http://www.scielo.br/scielo.php?script=sci_arttext\&pid=S1414-

$81452017000100202 \& \operatorname{lng}=$ en\&nrm=isso. Acesso em 23 mai. 2020.

SOARES, Joice. Ribeirão Preto apresenta perfil diferente de mortalidade materna. Jornal da Usp. São Paulo, p. 0-0. 21 out. 2019. Disponível em: jornal.usp.br/?p=279638. Acesso em: 23 mai. 2020.

LIMA, Laís Montenegro et al. Humanized care for women in abortion: a reflective analysis. Journal of Nursing UFPE on line, [S.1.], v. 11, n. 12, p. 5074-5078, dez. 2017. ISSN 1981-8963. Disponível em: https://periodicos.ufpe.br/revistas/revistaenfermagem/article/view/25126. Acesso em: 17 mai. 2020.

LUNA, Naara. O julgamento no Supremo do aborto de anencéfalo - ADPF 54: uma etnografia da religião no espaço público. Horizontes Antropológicos, Porto Alegre, v. 24, n. 52, p. 165-197, Dec. 2018. Disponível em: http://www.scielo.br/scielo.php?script=sci_arttext\&pid=S010471832018000300165\&lng=en\&nrm=iso. Acesso em: 23 mai. 2020.

MACHIN, Rosana; COUTO, Márcia Thereza; ROCHA, Ana Luísa Smith e COSTA, Maria Renata Mencacci. Formação médica e assistência aos processos de abortamento: a perspectiva de residentes de duas universidades públicas em São Paulo, Brasil. Interface (Botucatu), Botucatu, v. 23, e180370, 2019. Disponível em: http://www.scielo.br/scielo.php?script=sci_arttext\&pid=S141432832019000100243\&lng=en\&nrm=iso. Acesso em: 23 mai. 2020.

MADEIRO, Alberto Pereira; RUFINO, Andréa Cronemberger. Maus-tratos e discriminação na assistência ao aborto provocado: a percepção das mulheres em Teresina, Piauí, Brasil. Ciência e Saúde Coletiva, Rio de Janeiro, v. 22, n. 8, p. 2771-2780, ago. 2017. Disponível em: http://dx.doi.org/10.1590/1413-81232017228.04252016. Acesso em: 24 set. 2018.

PATERSON J. G.; ZDERAD, L. T. Enfermería humanística. México: Limusa, 1979.

PATERSON J. G.; ZDERAD, L. T. Humanistic Nursing. New York: NLN, 1988.

PEREIRA, Adriana de Jesus. O Papel do Profissional Enfermeiro Frente ao Aborto em seus Aspectos Jurídicos, Físico e Emocionais. Revista Científica Multidisciplinar Núcleo do Conhecimento. Ano 03, Ed. 08, v. 07, p. 95-115, Agosto de 2018. Disponível em:

https://www.nucleodoconhecimento.com.br/saude/profissional-enfermeiro. Acesso em 16 mai. 2020. 
SANTOS, C.; Rocha, K.; Silva, C. Atenção Humanizada às Mulheres, Adolescentes, Jovens em Situação de Abortamento e Acesso ao Aborto Legal. Revista Multidisciplinar Pey Këyo Científico ISSN 2525-8508, América do Norte, 62004 2020. Disponível em:

http://revistaadmmade.estacio.br/index.php/pkcroraima/article/viewArticle/8125. Acesso em 16 mai. 2020.

SANTOS, William Araújo. Análise epidemiológica da mortalidade fetal na 4a região de saúde do Rio Grande do Norte no período de 2007 a 2016. 2019. Disponível em:

https://monografias.ufrn.br/jspui/bitstream/123456789/8913/1/AnaliseEpidemiologicaDaMortalidadeF etal_Santos_2019.pdf. Acesso em: 20 mai. 2020.

SILVA, Lucivani Ferreira; FERREIRA, Crystopher Alves Lobo; FREITAS, Elisângela Antônio de Oliveira. A enfermagem frente ao aborto legal. 2019. Disponível em:

https://www.periodicos.univag.com.br/index.php/CONNECTIONLINE/article/download/1401/1504. Acesso em: 20 mai. 2020.

VASQUES, T. C.; LUNARDI, V.; SILVA, P.; CARVALHO, K.; ALGERI, S. Cuidados paliativos e teoria humanística na enfermagem. Revista Enfermagem Atual In Derme, v. 91, n. 29, 6 abr. 2020. Disponível em: http://www.revistaenfermagematual.com.br/index.php/revista/article/view/467/601.

Acesso em 19 mai. 2020. 